Supporting Information

\title{
Nanoscale Heterogeneities and Composition-Reactivity Relationships in Copper Vanadate Photoanodes
}

\author{
Johanna Eichhorn, ${ }^{\mathrm{a}, \mathrm{b}}$ Chang-Ming Jiang, ${ }^{\mathrm{a}, \mathrm{b}}$ Jason K. Cooper, ${ }^{\mathrm{a}}$ Ian D. Sharp, ${ }^{\mathrm{b}}$ and Francesca M. Toma ${ }^{\mathrm{a}}$ \\ ${ }^{a}$ Chemical Sciences Division and Joint Center for Artificial Photosynthesis, Lawrence Berkeley National Laboratory, 1 \\ Cyclotron Road, Berkeley, California 94720, United States. \\ ${ }^{\mathrm{b}}$ Walter Schottky Institute and Physics Department, Technische Universität München, Am Coulombwall 4, 85748 \\ Garching, Germany.
}

*fmtoma@lbl.gov

Table S1. Average transition metal composition $\mathrm{Cu} /(\mathrm{Cu}+\mathrm{V})$ of different $\mathrm{Cu}_{5} \mathrm{~V}_{2} \mathrm{O}_{10}$ films on ITO and $\mathrm{SiN} \mathrm{N}_{\mathrm{x}}$ determined by coupled plasma mass spectroscopy (ICP-MS). The films were deposited simultaneously on both substrates.

\begin{tabular}{c|c|c}
\hline Composition & ITO & SiNx \\
\hline Stoichiometric & $0.717 \pm 0.003$ & $0.723 \pm 0.003$ \\
Cu-deficient & $0.713 \pm 0.002$ & $0.710 \pm 0.003$ \\
Slightly Cu-rich & $0.738 \pm 0.004$ & $0.731 \pm 0.005$ \\
Highly Cu-rich & $0.798 \pm 0.003$ & $0.787 \pm 0.012$ \\
\hline
\end{tabular}
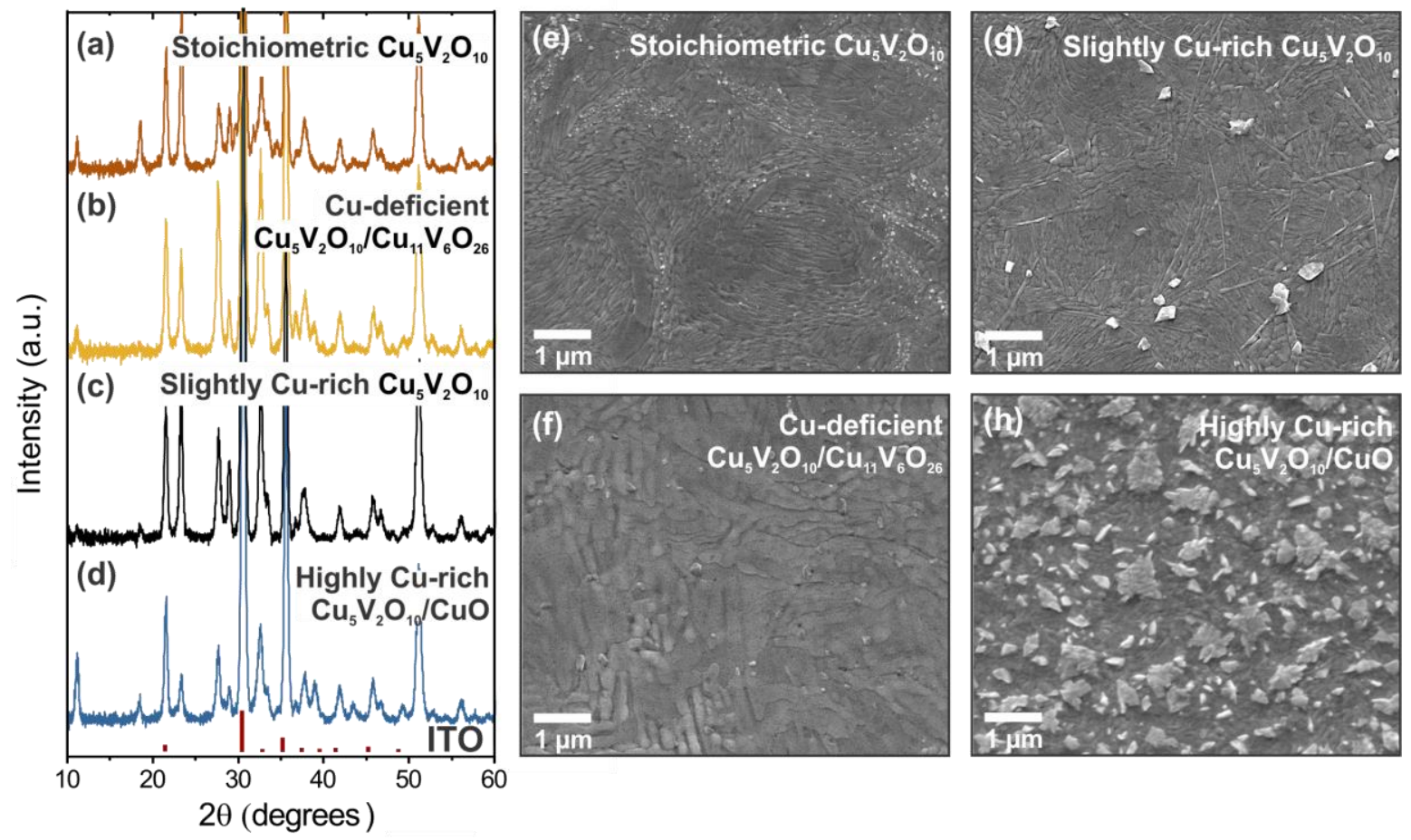

Figure S1. (a-d) X-ray diffraction pattern and (e-h) SEM images of copper vanadate thin films on ITO coated glass substrates for different $\mathrm{Cu}$ concentrations, namely stoichiometric $\mathrm{Cu}_{5} \mathrm{~V}_{2} \mathrm{O}_{10}$, Cu-deficient $\mathrm{Cu}_{5} \mathrm{~V}_{2} \mathrm{O}_{10} / \mathrm{Cu}_{11} \mathrm{~V}_{6} \mathrm{O}_{26}$, slightly Cu-rich $\mathrm{Cu}_{5} \mathrm{~V}_{2} \mathrm{O}_{10}$, and highly $\mathrm{Cu}$-rich $\mathrm{Cu}_{5} \mathrm{~V}_{2} \mathrm{O}_{10} / \mathrm{CuO}$. The diffraction peaks at $21^{\circ}, 30^{\circ}, 35^{\circ}$, and $51^{\circ}$ correspond to the ITO substrate. 


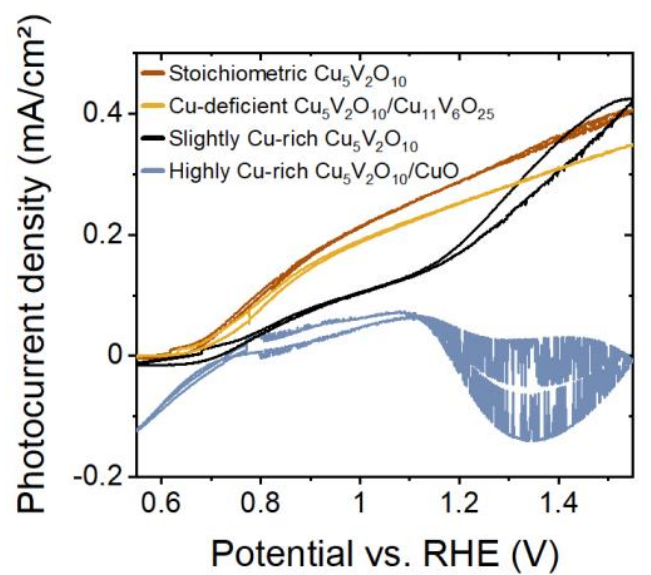

Figure S2. Photocurrent of stoichiometric $\mathrm{Cu}_{5} \mathrm{~V}_{2} \mathrm{O}_{10}$, Cu-deficient $\mathrm{Cu}_{5} \mathrm{~V}_{2} \mathrm{O}_{10} / \mathrm{Cu}_{11} \mathrm{~V}_{6} \mathrm{O}_{26}$, slightly $\mathrm{Cu}$-rich $\mathrm{Cu}_{5} \mathrm{~V}_{2} \mathrm{O}_{10}$, and highly $\mathrm{Cu}$-rich $\mathrm{Cu}_{5} \mathrm{~V}_{2} \mathrm{O}_{10} / \mathrm{CuO}$. The $J V$-characteristics were recorded in sulfite $0.1 \mathrm{M}$ sodium borate $\left(\mathrm{NaB}_{i}, \mathrm{pH} 9.4\right)$ with $0.1 \mathrm{M}$ sodium.

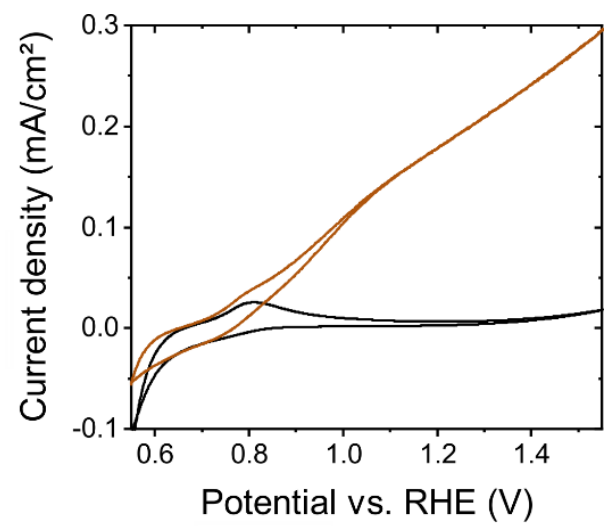

Figure S3. Cyclic voltammetry of highly Cu-deficient $\mathrm{Cu}_{5} \mathrm{~V}_{2} \mathrm{O}_{10} / \mathrm{Cu}_{11} \mathrm{~V}_{6} \mathrm{O}_{26}$ on ITO glass with $\mathrm{Cu} /(\mathrm{Cu}+\mathrm{V})$ ratio of 0.688 . The JVcharacteristics were recorded in sulfite $0.1 \mathrm{M}$ sodium borate $\left(\mathrm{NaB}_{\mathrm{i}}, \mathrm{pH} 9.4\right)$ with $0.1 \mathrm{M}$ sodium in the dark and under $\mathrm{AM} 1.5$ simulated solar irradiation at 1 sun intensity $\left(100 \mathrm{~mW} \mathrm{~cm}^{-2}\right)$.
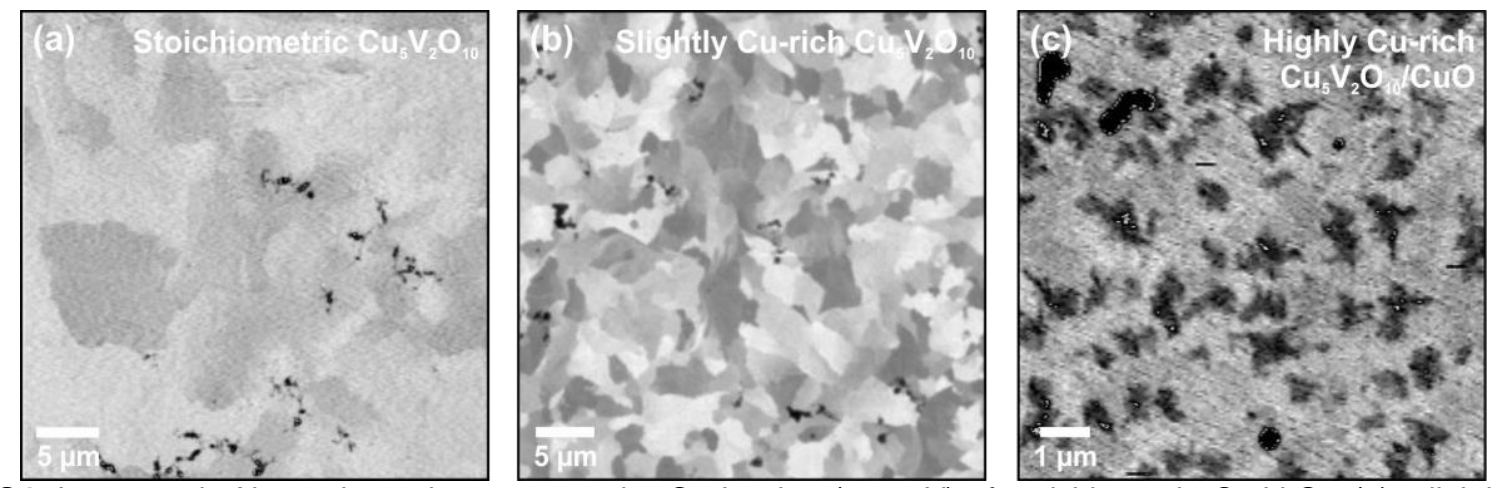

Figure S4. Large scale X-ray absorption maps at the $\mathrm{Cu}$ L-edge (932 eV) of stoichiometric $\mathrm{Cu}_{5} \mathrm{~V}_{2} \mathrm{O}_{10}(\mathrm{a})$, slightly $\mathrm{Cu}$-rich $\mathrm{Cu}_{5} \mathrm{~V}_{2} \mathrm{O}_{10}$ (b), and highly $\mathrm{Cu}$-rich $\mathrm{Cu}_{5} \mathrm{~V}_{2} \mathrm{O}_{10} / \mathrm{CuO}$ (c) photoelectrodes. 


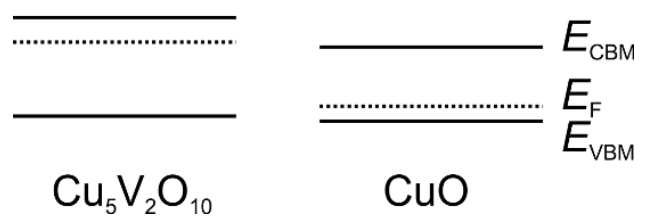

Figure S5. Scheme of the band energy diagram for $\mathrm{Cu}_{5} \mathrm{~V}_{2} \mathrm{O}_{10}$ and $\mathrm{CuO}$ relative to vacuum.
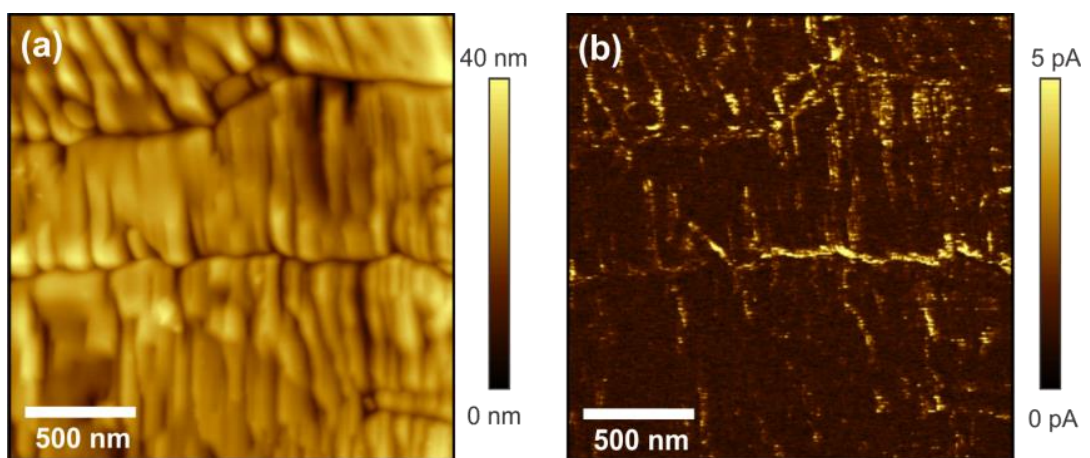

Figure S6. Topography (a) and photocurrent (b) maps of stoichiometric $\mathrm{Cu}_{5} \mathrm{~V}_{2} \mathrm{O}_{10}$ photoanodes. 